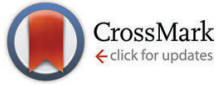

Cite this: Chem. Commun., 2015, 51, 8311

Received 17th March 2015, Accepted 8th April 2015

DOI: $10.1039 / c 5 c c 02236 c$

www.rsc.org/chemcomm

\section{Solubilisation of a 2,2-diphenyl-1-picrylhydrazyl radical in water by $\beta$-cyclodextrin to evaluate the radical-scavenging activity of antioxidants in aqueous media†}

\author{
Ikuo Nakanishi, ${ }^{\text {a }}$ Kei Ohkubo, ${ }^{\text {bc }}$ Kohei Imai, ${ }^{d}$ Masato Kamibayashi, ${ }^{e}$ \\ Yasuo Yoshihashi, ${ }^{\dagger}$ Ken-ichiro Matsumoto, ${ }^{a}$ Kiyoshi Fukuhara, ${ }^{d}$ Katsuhide Terada, \\ Shinobu Itoh, ${ }^{b}$ Toshihiko Ozawa ${ }^{\mathrm{g}}$ and Shunichi Fukuzumi*bchi
}

\begin{abstract}
A 2,2-diphenyl-1-picrylhydrazyl radical (DPPH॰) was successfully solubilised in water by $\beta$-cyclodextrin $(\beta-C D)$. DPPH $/ \beta-C D$ thus obtained was demonstrated to be a powerful tool to evaluate the antioxidative activity of water-soluble antioxidants, such as ascorbate and Trolox, in aqueous buffer solutions.
\end{abstract}

A relatively stable radical, 2,2-diphenyl-1-picrylhydrazyl ( $\left.\mathrm{DPPH}^{\circ}\right)$ (Scheme 1), is frequently used as a reactivity model of reactive oxygen species (ROS) to evaluate the radical-scavenging activity of antioxidants. ${ }^{1-6} \mathrm{DPPH}^{\bullet}$ shows a characteristic absorption band at around $520 \mathrm{~nm}$, which disappears upon addition of compounds with radical-scavenging activity. However, alcoholic cosolvents, such as methanol and ethanol, are required to use $\mathrm{DPPH}^{\bullet}$ in aqueous systems due to its little solubility in water. ${ }^{7-9}$ In such a case, concentrated buffer solutions cannot be used to control the $\mathrm{pH}$ of the reaction systems because buffer salts are precipitated in the alcoholic reaction media. Cyclodextrins (CDs) are cyclic oligosaccharides that have a hydrophobic internal cavity and a hydrophilic external surface. Thus, CDs form inclusion complexes

\footnotetext{
${ }^{a}$ Radio-Redox-Response Research Team, Advanced Particle Radiation Biology Research Program, Research Center for Charged Particle Therapy, National Institute of Radiological Sciences (NIRS), Inage-ku, Chiba 263-8555, Japan. E-mail: nakanis@nirs.go.jp; Fax: +81-43-255-6819; Tel: +81-43-206-3131

${ }^{b}$ Department of Material and Life Science, Graduate School of Engineering, Osaka University, Suita, Osaka 565-0871, Japan

${ }^{c}$ ALCA and SENTAN, Japan Science and Technology Agency (JST), Suita, Osaka 565-0871, Japan

${ }^{d}$ School of Pharmacy, Showa University, Shinagawa-ku, Tokyo 142-8555, Japan

${ }^{e}$ Pharmaceutical Manufacturing Chemistry, Kyoto Pharmaceutical University, Kyoto 607-8414, Japan

${ }^{f}$ Department of Pharmaceutics, Faculty of Pharmaceutical Sciences, Toho University, Funabashi, Chiba 274-8510, Japan

${ }^{g}$ Division of Oxidative Stress Research, Showa Pharmaceutical University, Machida, Tokyo 194-8543, Japan

${ }^{h}$ Department of Bioinspired Science, Ewha Womans University, Seoul 120-750, Korea

${ }^{i}$ Faculty of Science and Technology, Meijo University, Shiogamaguchi, Tempaku, Nagoya, Aichi 468-8502, Japan

$\dagger$ Electronic supplementary information (ESI) available: Experimental details and EPR spectra at room temperature (Fig. S1). See DOI: 10.1039/c5cc02236c
}

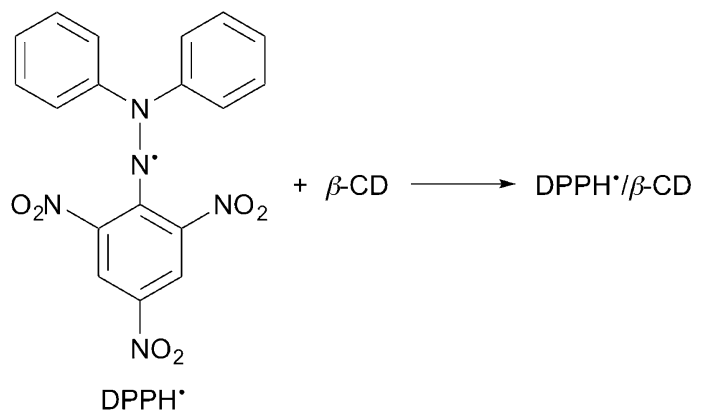

Scheme 1 Incorporation of DPPH• into $\beta$-cyclodextrin ( $\beta-C D)$.

with a wide range of hydrophobic molecules and solubilise them in water. ${ }^{10,11}$ We report herein the solubilisation of $\mathrm{DPPH}^{\bullet}$ in water using $\beta$-cyclodextrin ( $\beta$-CD: Scheme 1 ), which consists of 7 glucopyranoside units. The scavenging reaction of $\beta$-CDsolubilised $\mathrm{DPPH}^{\bullet}\left(\mathrm{DPPH}^{\bullet} / \beta-\mathrm{CD}\right)$ by water-soluble antioxidants in phosphate buffer solution (0.1 M, pH 7.4) demonstrated that $\mathrm{DPPH}^{\bullet} / \beta$-CD would be a powerful tool to evaluate the antioxidative activity in aqueous media without alcoholic cosolvents.

$15 \mathrm{~mL}$ of boiling water (Milli-Q) or a phosphate buffer solution (0.1 $\mathrm{M}, \mathrm{pH}$ 7.4) was added to the mixture containing $\mathrm{DPPH}^{\bullet}$ $(0.23 \mathrm{mmol})$ and $\beta-\mathrm{CD}(0.35 \mathrm{mmol})$, and the suspension was cooled to room temperature. The filtration of the suspension using a membrane filter (pore size: $0.22 \mu \mathrm{m}$ ) gave a deep violet solution. This solution showed an absorption band at $527 \mathrm{~nm}$, which is diagnostic of $\mathrm{DPPH}^{\bullet}$ (Fig. 1). Thus, $\mathrm{DPPH}^{\bullet}$ could be solubilised in water by $\beta$-CD. A significant red shift of the band due to $\mathrm{DPPH}^{\bullet} / \beta$-CD as compared to those of free $\mathrm{DPPH}^{\bullet}$ in $n$-hexane (509 nm), MeOH (516 nm), EtOH (517 nm) and acetonitrile $(519 \mathrm{~nm})$ suggests that the $>\mathrm{N}-\mathrm{N}^{\bullet}-$ moiety of $\mathrm{DPPH}^{\bullet}$ may exist outside of the $\beta$-CD cavity and strongly interact with water. The concentration of $\mathrm{DPPH}^{\bullet}$ was estimated to be $5.9 \times$ $10^{-5} \mathrm{M}$ by using the $\varepsilon$ value of $11000 \mathrm{M}^{-1} \mathrm{~cm}^{-1}$ determined for $\mathrm{DPPH}^{\bullet}$ in a $1: 1$ ethanol-buffer solution. ${ }^{9}$ When $\beta$-CD was replaced by $\alpha$ - or $\gamma$-CD, which consists of 6 or 8 glucopyranoside units and thus has a smaller or bigger hydrophobic cavity than $\beta-C D$, 


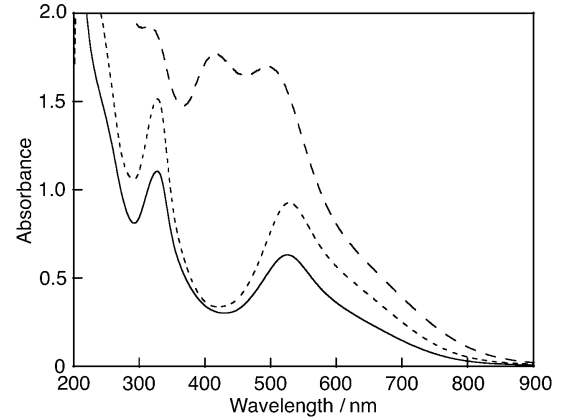

Fig. 1 UV-vis spectra of extracts of the mixture of $\mathrm{DPPH} \bullet(0.23 \mathrm{mmol})$ and $\beta-C D(0.45 \mathrm{mmol})$ in $15 \mathrm{~mL}$ of boiling phosphate buffer (0.1 M, pH 7.4) (-), acetate buffer (50 mM, pH 4.4) (---) and borate buffer (14 mM, pH 9.1) (- - -). (a)

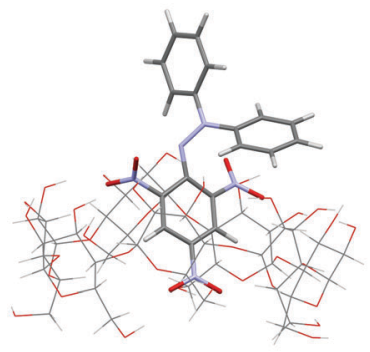

(b)

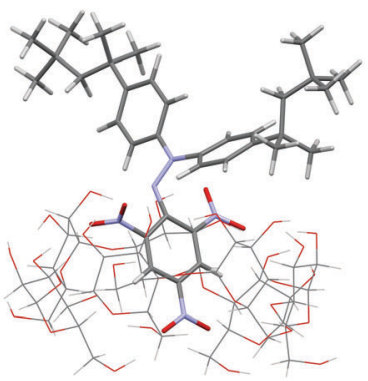

Fig. 2 Optimised structures of the inclusion complex of (a) $\mathrm{DPPH} \bullet$ with $\beta-C D$ and (b) DOPPH ${ }^{\bullet}$ with $\beta-C D$ calculated by DFT (UB3LYP/3-21G:C-PCM solvation model parameterised for water).

$\mathrm{DPPH}^{\bullet}$ was not solubilised in water. The 2,2-di(4-tert-octylphenyl)1-picrylhydrazyl radical $\left(\mathrm{DOPPH}^{*}\right)$ could not be solubilised in water by $\beta$-CD in the same manner, either. Fig. 2a shows an optimised structure of the inclusion complex of $\mathrm{DPPH}^{\bullet}$ with $\beta$-CD calculated by the density functional theory (DFT) (UB3LYP/ 3-21G:C-PCM solvation model parameterised for water) (see the ESI†). The picryl moiety of $\mathrm{DPPH}^{\bullet}$ is incorporated into the hydrophobic cavity of $\beta$-CD. DOPPH ${ }^{\bullet}$ is also incorporated into $\beta$-CD as shown in Fig. $2 \mathrm{~b}$. The calculated association energy between $\mathrm{DPPH}^{\bullet}$ and $\beta$-CD $\left(-31 \mathrm{kcal} \mathrm{mol}^{-1}\right)$ by DFT is significantly less negative than that between $\mathrm{DOPPH}^{\bullet}$ and $\beta$-CD $\left(-44 \mathrm{kcal} \mathrm{mol}^{-1}\right)$. These theoretical results suggest that $\mathrm{DOPPH}^{\bullet}$ may not be solubilised by $\beta$-CD due to the hydrophobic tert-octyl groups. $\mathrm{DPPH}^{\bullet}$ solubilised by $\beta$-CD in water or the phosphate buffer solution $(0.1 \mathrm{M}, \mathrm{pH} 7.4)$ is stable at least for several days at room temperature. When a boiling acetate buffer solution (50 mM, pH 4.4) was used instead of the phosphate buffer, DPPH ${ }^{\bullet}$ could also be solubilised by $\beta$-CD (Fig. 1). On the other hand, a brown solution with absorption bands at 416 and $505 \mathrm{~nm}$ was obtained using the boiling borate buffer solution (14 mM, pH 9.1) as shown in Fig. 1 . This suggests that $\mathrm{DPPH}^{\bullet}$ is unstable under basic conditions as reported previously. ${ }^{9}$ In fact, addition of $0.75 \mathrm{~mL}$ of a borate buffer solution (0.1 M, pH 9.1) to DPPH $/ \beta$-CD in water (Milli-Q) (2.3 mL) resulted in a gradual decrease in the absorption band at $527 \mathrm{~nm}$, accompanied by an increase in the band at $412 \mathrm{~nm}$ with clear isosbestic points at 252, 304, 346 and $491 \mathrm{~nm}$ as shown in Fig. 3. The one-electron reduced $\mathrm{DPPH}^{\bullet}\left(\mathrm{DPPH}^{-}\right)$is reported to have an

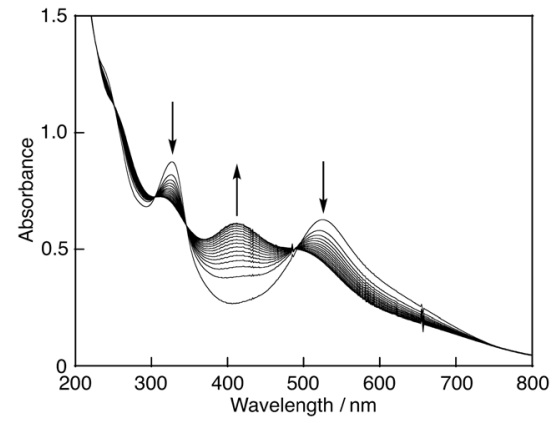

Fig. 3 Spectral change observed for $\mathrm{DPPH} \bullet / \beta-\mathrm{CD}\left(5.8 \times 10^{-5} \mathrm{M}\right)$ in borate buffer (25 mM, pH 9.1) at $298 \mathrm{~K}$. Interval: $20 \mathrm{~min}$. (a)

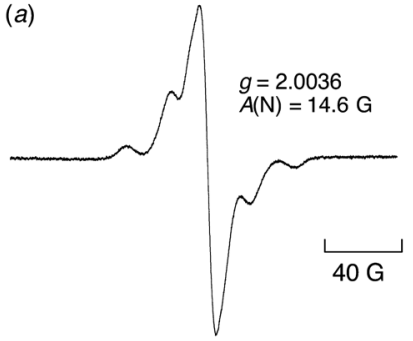

(b)

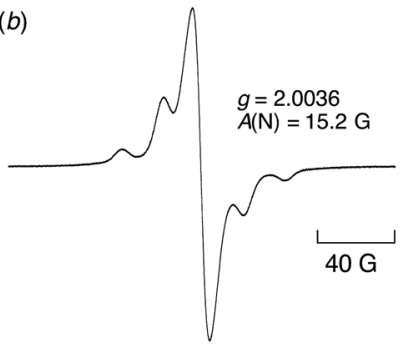

Fig. 4 EPR spectra of (a) DPPH $/ \beta-C D\left(1.0 \times 10^{-5} \mathrm{M}\right)$ in distilled water at $77 \mathrm{~K}$ and (b) $\mathrm{DPPH}^{\bullet}\left(1.0 \times 10^{-5} \mathrm{M}\right)$ in $\mathrm{MeOH}$ at $77 \mathrm{~K}$.

absorption band at $426 \mathrm{~nm}$ in a $1: 1$ ethanol-buffer solution, ${ }^{9}$ suggesting that $\mathrm{DPPH}^{-}$may be included in the products. However, the detailed reaction mechanism of $\mathrm{DPPH}^{\bullet}$ under basic conditions is under investigation and will be reported elsewhere.

The EPR spectrum of $\mathrm{DPPH}^{\bullet} / \beta$-CD observed in water at room temperature has the same $g$ value (2.0036) and hyperfine coupling constant $(7.8 \mathrm{G})$ as those of $\mathrm{DPPH}^{\bullet}$ in $\mathrm{MeOH}(2.0036$ and $7.9 \mathrm{G}$, respectively) (see the Fig. S1, ESI $\dagger$ ). A slightly small hyperfine coupling constant (14.6 G) was observed in water as compared to that in $\mathrm{MeOH}(15.2 \mathrm{G}$ ) for the EPR spectra recorded at $77 \mathrm{~K}$ (Fig. 4).

When ascorbic acid $\left(\mathrm{AscH}_{2}\right)$ was added to the phosphate buffer solution $(0.1 \mathrm{M}, \mathrm{pH} 7.4)$ of $\mathrm{DPPH}^{*} / \beta-\mathrm{CD}$, the band at $527 \mathrm{~nm}$ disappeared immediately with clear isosbestic points at 320,338 and $431 \mathrm{~nm}$ as shown in Fig. 5a. Since the $\mathrm{p} K_{\mathrm{a}}$ value of $\mathrm{AscH}_{2}$ is reported to be $4.1,{ }^{12} \mathrm{AscH}_{2}$ undergoes deprotonation and exists in its anionic form, $\mathrm{AscH}^{-}$, in phosphate buffer solution $(0.1 \mathrm{M}$, $\mathrm{pH}$ 7.4). Thus, this spectral change indicates that $\mathrm{AscH}^{-}$efficiently scavenged $\mathrm{DPPH}^{\bullet}$ in phosphate buffer [eqn (1)]. When $\mathrm{AscH}^{-}$was replaced by Trolox, a water-soluble analogue of $\alpha$-tocopherol (vitamin E), a similar spectral change was observed due to the scavenging reaction of $\mathrm{DPPH}^{\bullet}$ by Trolox [Fig. $5 \mathrm{~b}$ and eqn (2)]. ${ }^{13}$

$$
\begin{gathered}
\mathrm{DPPH}^{\bullet} / \beta-\mathrm{CD}+\mathrm{AscH}^{-} \rightarrow \mathrm{DPPH}_{2} / \beta-\mathrm{CD}+\mathrm{Asc}^{\bullet-} \\
\mathrm{DPPH}^{\bullet} / \beta-\mathrm{CD}+\operatorname{Trolox} \rightarrow \mathrm{DPPH}_{2} / \beta-\mathrm{CD}+\operatorname{Trolox}(-\mathrm{H})^{\bullet}
\end{gathered}
$$

Spectral titrations (insets of Fig. 3a and b) show the same stoichiometry with both antioxidants, the $\mathrm{DPPH}^{\bullet} /$ antioxidant molar ratio being $2: 1{ }^{7}$ The decay of the absorbance at $527 \mathrm{~nm}$ monitored by a stopped-flow technique obeyed pseudo-first-order kinetics, 

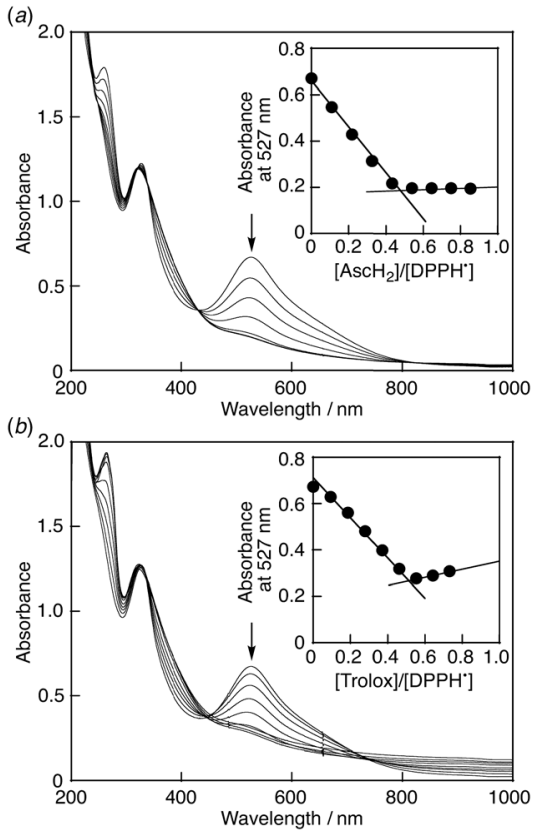

Fig. 5 Spectral changes observed upon addition of (a) $\mathrm{AscH}_{2}(0-5.4 \times$ $\left.10^{-5} \mathrm{M}\right)$ or (b) Trolox $\left(0-4.6 \times 10^{-5} \mathrm{M}\right)$ to $\mathrm{DPPH} / \beta-\mathrm{CD}\left(6.3 \times 10^{-5} \mathrm{M}\right)$ in phosphate buffer $(0.1 \mathrm{M}, \mathrm{pH}$ 7.4). Insets: plots of the absorbance at $527 \mathrm{~nm}$ vs. (a) $\left[\mathrm{AscH}_{2}\right] /\left[\mathrm{DPPH}^{\bullet}\right]$ and (b) $[\text { Trolox]/[DPPH }]^{\bullet}$.

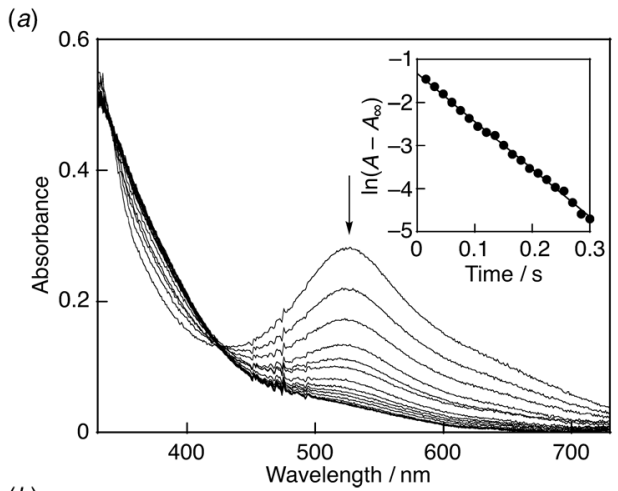

(b)

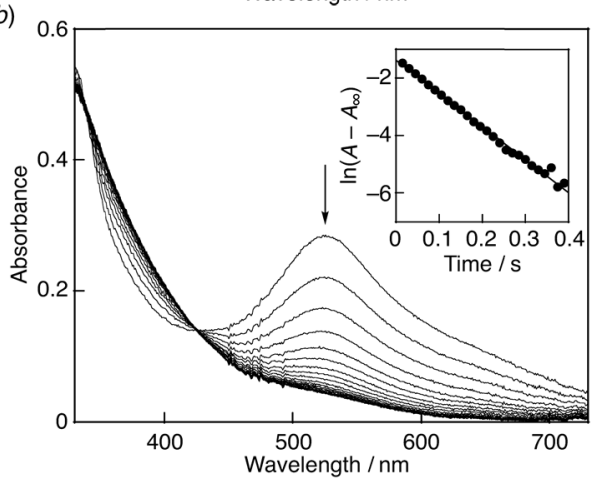

Fig. 6 Spectral changes (interval: $25 \mathrm{~ms}$ ) observed during reactions of (a) $\mathrm{AsCH}_{2}\left(1.4 \times 10^{-3} \mathrm{M}\right)$ with $\mathrm{DPPH} \bullet / \beta-\mathrm{CD}\left(2.6 \times 10^{-5} \mathrm{M}\right)$ and (b) Trolox $\left(6.3 \times 10^{-4} \mathrm{M}\right)$ with $\mathrm{DPPH} \bullet / \beta-\mathrm{CD}\left(3.0 \times 10^{-5} \mathrm{M}\right)$ in phosphate buffer $(0.1 \mathrm{M}$, $\mathrm{pH} 7.4$ ) at $298 \mathrm{~K}$. Insets: the first-order plots of the absorbance at $527 \mathrm{~nm}$.

when the concentration of $\mathrm{AscH}_{2}\left(\left[\mathrm{AscH}_{2}\right]\right)$ was maintained at more than a 10 -fold excess of $\mathrm{DPPH}^{\bullet} / \beta$-CD concentration (Fig. 6a).
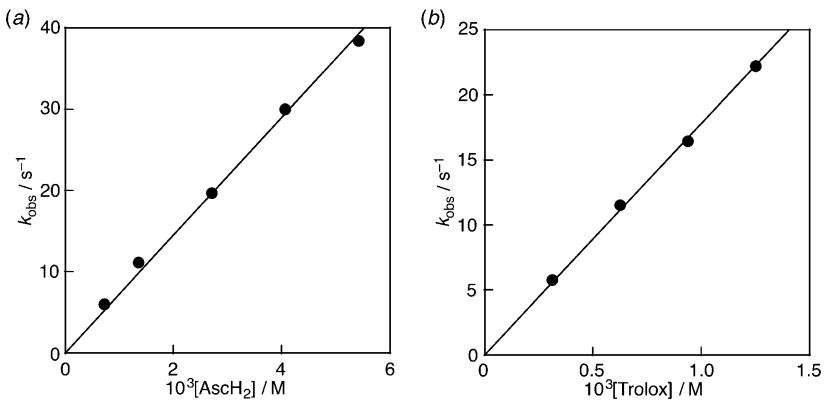

Fig. 7 Plots of $k_{\mathrm{obs}} v s$. (a) $\left[\mathrm{AscH}_{2}\right]$ and (b) [Trolox].

The pseudo-first-order rate constant $\left(k_{\mathrm{obs}}\right)$ linearly increased with increasing $\left[\mathrm{AscH}_{2}\right]$ (Fig. 7a). From the slope of the linear plot the second-order rate constant $(k)$ for the scavenging of $\mathrm{DPPH}^{*} / \beta$-CD by $\mathrm{AscH}_{2}$ was determined in a phosphate buffer $(0.1 \mathrm{M}, \mathrm{pH} 7.4)$ to be $7.2 \times 10^{3} \mathrm{M}^{-1} \mathrm{~s}^{-1}$. The $k$ value for Trolox was also determined in the same manner to be $1.8 \times 10^{4} \mathrm{M}^{-1} \mathrm{~s}^{-1}$ (Fig. $6 \mathrm{~b}$ and $7 \mathrm{~b}$ ), which is exactly the same as that measured in a $1: 1$ ethanolbuffer (pH 7.4) solution. ${ }^{9,14}$ Thus, $\beta$-CD does not inhibit the reaction of $\mathrm{DPPH}^{\bullet}$ with the antioxidants, while the stability and reactivity of nitroxyl radicals were reported to be significantly changed by the complexation with cyclodextrins. ${ }^{15}$

In summary, $\beta$-CD-solubilised $\mathrm{DPPH}^{\bullet}$ in water has been demonstrated to be a powerful tool to evaluate the antioxidative activity of antioxidants in aqueous media, especially in highly concentrated buffer solutions without precipitation of buffer salts.

This work was partially supported by Grant-in-Aid (No. 26460056 to I.N., 26620154 and 266288037 to K.O.) from the Ministry of Education, Culture, Sports, Science and Technology, Japan, and ALCA and SENTAN projects from JST.

\section{Notes and references}

1 M. S. Blois, Nature, 1958, 181, 1199.

2 (a) K. U. Ingold and D. A. Pratt, Chem. Rev., 2014, 114, 9022; (b) G. Litwinienko and K. U. Ingold, Acc. Chem. Res., 2007, 40, 222.

3 (a) E. van Wenum, R. Jurczakowski and G. Litwinienko, J. Org. Chem., 2013, 78, 9102; (b) M. Musialik, R. Kuzmicz, T. S. Pawłowski and G. Litwinienko, J. Org. Chem., 2009, 74, 2699; (c) P. Mulder, G. Litwinienko, S. Lin, P. D. MacLean, L. R. Barclay and K. U. Ingold, Chem. Res. Toxicol., 2006, 19, 79; (d) G. Litwinienko and K. U. Ingold, J. Org. Chem., 2005, 70, 8982; (e) M. Musialik and G. Litwinienko, Org. Lett., 2005, 7, 495; $(f)$ G. Litwinienko and K. U. Ingold, J. Org. Chem., 2004, 69, 5888; $(g)$ G. Litwinienko and K. U. Ingold, J. Org. Chem., 2003, 68, 3433.

4 (a) R. Amorati, S. Menichetti, C. Viglianisi and M. C. Foti, Chem. Commun., 2012, 48, 11904; (b) M. C. Foti, Int. J. Chem. Kinet., 2012, 44, 524; (c) V. D. Kancheva, L. Saso, S. E. Angelova, M. C. Foti, A. Slavova-Kasakova, C. Daquino, V. Enchev, O. Firuzi and J. Nechev, Biochemie, 2012, 94, 403; (d) M. C. Foti, C. Daquino, G. A. DiLabio and K. U. Ingold, Org. Lett., 2011, 13, 4826; (e) M. C. Foti, R. Amorati, G. F. Pedulli, C. Daquino, D. A. Pratt and K. U. Ingold, J. Org. Chem., 2011, 75, 4434; $(f)$ M. C. Foti, C. Daquino, I. D. Mackie, G. A. DiLabio and K. U. Ingold, J. Org. Chem., 2008, 73, 9270; $(g)$ M. C. Foti and C. Daquino, Chem. Commun., 2006, 3252; (h) M. C. Foti, C. Daquino and C. Geraci, J. Org. Chem., 2004, 69, 2309; (i) M. C. Foti, L. R. Barlay and K. U. Ingold, J. Am. Chem. Soc., 2002, 124, 12881.

5 (a) T. Waki, S. Kobayashi, K. Matsumoto, T. Ozawa, T. Kamada and I. Nakanishi, Chem. Commun., 2013, 49, 9842; (b) H. P. Indo, I. Nakanishi, K. Ohkubo, H. Yen, M. Nyui, S. Manda, K. Matsumoto, K. Fukuhara, K. Anzai, N. Ikota, H. Matsui, Y. Minamiyama, A. Nakajima, H. Ichikawa, S. Fukuzumi, T. Ozawa, C. Mukai and 
H. J. Majima, RSC Adv., 2013, 3, 4535; (c) T. Kawashima, S. Manda, Y. Uto, K. Ohkubo, H. Hori, K. Matsumoto, K. Fukuhara, N. Ikota, S. Fukuzumi, T. Ozawa, K. Anzai and I. Nakanishi, Bull. Chem. Soc. Jpn., 2012, 85, 877; (d) T. Waki, I. Nakanishi, K. Matsumoto, J. Kitajima, T. Chikuma and S. Kobayashi, Chem. Pharm. Bull., 2012, 60, 37; (e) S. Kobayashi, T. Waki, I. Nakanishi, K. Matsumoto and K. Anzai, Chem. Pharm. Bull., 2010, 58, 1442; $(f)$ I. Nakanishi, T. Kawashima, K. Ohkubo, H. Kanazawa, K. Inami, M. Mochizuki, K. Fukuhara, H. Okuda, T. Ozawa, S. Itoh, S. Fukuzumi and N. Ikota, Org. Biomol. Chem., 2005, 3, 626.

6 S. B. Kedare and R. P. Singh, J. Food Sci. Technol., 2011, 48, 412 and references cited therein.

7 M. B. Arnao, Trends Food Sci. Technol., 2000, 11, 419.

8 D.-W. Li, F.-F. Tian, Y.-S. Ge, X.-L. Ding, J.-H. Li, Z.-Q. Xu, M.-F. Zhang, X.-L. Han, R. Li, F.-L. Jiang and Y. Liu, Chem. Commun., 2011, 47, 10713.

9 O. Friaa and D. Brault, Org. Biomol. Chem., 2006, 4, 2417.
10 G. Crini, Chem. Rev., 2014, 114, 10940 and references cited therein. 11 I. Nakanishi, S. Fukuzumi, T. Konishi, K. Ohkubo, M. Fujitsuka, O. Ito and N. Miyata, J. Phys. Chem. B, 2002, 106, 2372.

12 (a) C. Creutz, Inorg. Chem., 1981, 20, 4449; (b) N. H. Williams and J. K. Yandell, Aust. J. Chem., 1982, 35, 1133.

13 Clear isosbestic points such as those in Fig. 3a were not observed due to relatively poor solubility of Trolox in phosphate buffer as compared to $\mathrm{AscH}_{2}$.

14 For $2: 1$ and $3: 1$ ethanol-water mixtures, the $k$ values were reported to be $8.6 \times 10^{3}$ and $7.0 \times 10^{3} \mathrm{M}^{-1} \mathrm{~s}^{-1}$, respectively. See ref. 9 .

15 (a) M. Spulber and S. Schlick, J. Phys. Chem. A, 2010, 114, 6217; (b) D. Bardelang, L. Charles, J.-P. Finet, L. Jicsinszky, H. Karoui, S. R. A. Marque, V. Monnier, A. Rockenbauer, R. Rosas and P. Tordo, Chem.- Eur. J., 2007, 13, 9344; (c) H. Karoui and P. Tordo, Tetrahedron Lett., 2004, 45, 1043; (d) H. Karoui, A. Rockenbauer, S. Pietri and P. Tordo, Chem. Commun., 2002, 3030; (e) C. Ebel, K. U. Ingold, J. Michon and A. Rassat, Tetrahedron Lett., 1985, 26, 741. 